\title{
Baseline differences in characteristics and risk behaviors among people who inject drugs by syringe exchange program modality: an analysis of the Miami IDEA syringe exchange
}

\author{
Siddharth lyengar ${ }^{1 *}$ (D, Adam Kravietz ${ }^{1}$, Tyler S. Bartholomew ${ }^{1}$, David Forrest ${ }^{2}$ and Hansel E. Tookes ${ }^{3}$
}

\begin{abstract}
Background: In March of 2016, Florida passed the Infection Disease Elimination Act (IDEA), legalizing the formation of the first syringe exchange program in Florida, which opened in December of 2016 at a fixed site in Overtown, Miami. Since that time, the exchange expanded in April of 2017 to include a mobile van unit that provides the same services at different locations throughout Miami-Dade County.

Methods: Trained interviewers conducted face-to-face interviews from all first-time participants at the IDEA Exchange, both at the fixed site and the mobile van unit.

Results: Among 718 first-time enrollees, $74.8 \%$ were male, 52.1\% were non-Hispanic White, $85.9 \%$ completed high school, 59.8\% were unemployed, $42.1 \%$ were homeless, $54.2 \%$ reported an annual income of less than $\$ 15,000$, and the mean age was 38 years. Participants at the fixed site and mobile van unit reported differences in socioeconomic status, injection drug-related behaviors, and pre-existing hepatitis $\mathrm{C}$ virus (HCV) infection status.

Conclusions: Taken together, these results suggest that the mobile unit is capturing a subset of PWID in Miami that the fixed site is not, and vice-versa. As the opioid crisis extends into all demographics, such multimodal efforts to target various populations of PWID should be kept in mind, especially when unveiling future syringe exchanges in Florida and other late-adopting states.
\end{abstract}

\section{Background}

Multiple studies of syringe exchange programs (SEPs) in the USA and abroad have found SEPs to be associated with decreases in high-risk injection drug use behaviors without facilitating drug use [1-5]. SEPs have been found to be cost-effective ways to reduce the spread of communicable disease due to injection drug use, especially $\operatorname{HIV}[5,6]$. SEPs have been utilized in major cities throughout the world since the 1980s after the introduction of the highly successful SEP in Amsterdam in 1984 [7]. In North America, success was seen with SEPs in the 1990s in cities such as New York City,

\footnotetext{
* Correspondence: ski7@miami.edu

${ }^{1}$ Department of Public Health Sciences, University of Miami Miller School of Medicine, Miami, FL, USA

Full list of author information is available at the end of the article
}

Vancouver, and Baltimore and was highlighted by the US Surgeon General at that time [8]. Much attention has again been refocused on SEPs in the USA due to the current opioid crisis, which has been declared a national public health emergency.

In 2015, the Centers for Disease Control and Prevention (CDC) released its annual HIV Surveillance Report, which showed that Florida had the highest number of new HIV and AIDS diagnoses in 2014 of any state [9]. Data from the Florida Department of Health showed that 23\% of these HIV diagnoses and 19\% of these AIDS diagnoses occurred in Miami-Dade County [10]. Additionally, CDC data showed that Miami had the highest incidence of HIV in the USA in 2014 among all US cities and every subsequent year to date $[9,11,12]$. Studies also showed that the burden of

(C) The Author(s). 2019 Open Access This article is distributed under the terms of the Creative Commons Attribution 4.0 International License (http://creativecommons.org/licenses/by/4.0/), which permits unrestricted use, distribution, and 
HIV in Miami was heavily driven by injection drug use [13-15]. In light of this, the state of Florida passed the Infection Disease Elimination Act (IDEA) in March of 2016, which legalized the formation of a 5-year pilot syringe exchange program to be established in Miami-Dade County under the operation of the University of Miami. The program, as stipulated by law, is privately funded and operates using a strict 1:1 exchange model. This syringe exchange is the first of its kind in the state of Florida and became operational in December of 2016 at a fixed location Overtown, a predominantly underserved African-American neighborhood of Miami known for high rates of illicit drug activity and overdose deaths.

Responding to an increased demand for its services, the IDEA Exchange expanded via a mobile van unit, which became operational in April of 2017. While the mobile van unit has been stationed in multiple locations throughout Miami-Dade County, it primarily provides its services in Overtown, the same community as the fixed site. Previous data on mobile unit syringe exchange has shown that they can offer an additional modality with which to target hard-to-reach people who inject drugs (PWID) [16, 17]. Specifically, while the World Health Organization, Joint United Nations Programme on HIV/AIDS, and United Nations Office on Drugs and Crime have recommended the use of mobile SEPs, a recent critical review of mobile SEPs showed that the evidence regarding their efficacy is lacking [18]. The purpose of this study was to examine differences in sociodemographic factors, injection drug use behaviors, sexual risk behaviors, and HIV/HCV status between those surveyed at the mobile van unit and the fixed-site syringe exchange in order to better inform implementation of SEPs in late adopting states such as Florida.

\section{Methods}

This study analyzed data from a 42-item enrollment survey developed by the study's authors in conjunction with experts from other SEPs in the USA as well as peer educators and outreach workers who have experience working with PWID. These surveys assessed participant demographics, injection drug use behaviors, sexual behaviors, and HIV/HCV indicators. This analysis was submitted to the University of Miami Institutional Review Board (Study \#20160932) and determined not to be human subjects research.

\section{Study population}

Participants were a convenience sample of PWID who visited either the fixed site of the IDEA Exchange in Overtown, Miami, or the mobile van unit to enroll in the program. Participant eligibility criteria included enrollment in the IDEA Exchange program, age of 18 years or older, and ability to complete the interviewer-administered survey in English or Spanish. Enrollment surveys were administered prior to provision of harm reduction services. This study includes all 718 participants enrolled through April 2018 at the fixed site (591 participants) since its inception in December 2016 as well as the mobile van unit (127 participants) which became operational in April 2017. Sites of recruitment for the mobile van unit include weekly visits to the following Miami-Dade County cities/communities: Overtown, Liberty City, Florida City, Opa-Locka, Miami Beach, and Miami Gardens. No monetary incentives were provided for enrollment in the program.

\section{Study design}

The study's authors developed survey questions with input from experts at other harm reduction services as well as peer educators and outreach workers (i.e., individuals with expertise in SEP service provision as well as working with PWID) to design the 42-item survey and to train interviewers. Interviewers consisted of students and IDEA Exchange staff who underwent training to ensure standardized administration of the survey. Surveys were orally administered in a face-to-face interview and took approximately $15 \mathrm{~min}$ to complete. The interviews were conducted in private rooms either in the mobile van or the fixed site. No personal identifying information was collected from participants. Participants were assigned a four-digit unique identifier and given an identification card containing only this number that is used to keep records. These surveys assessed participant demographics, injection drug use behaviors, and HIV/HCV indicators, as required by state statute. Survey data was collected on electronic tablets using REDCap ${ }^{\circ}$ software. Upon completion of the survey, participants were able to participate in 1:1 exchange of syringes, receive sterile injection equipment, obtain an on-site $\mathrm{HCV} / \mathrm{HIV}$ test, and were counseled on $\mathrm{HCV} / \mathrm{HIV}$ prevention and harm reduction practices.

\section{Measures}

The outcomes for this study included any differences in baseline characteristics between PWID at the fixed site or the mobile van unit. Demographic data assessed participants' age, gender, race/ethnicity, marital status, sexual orientation, highest level of educational attainment, employment status, annual household income, housing status, insurance status, ZIP code of residence, and method in which they heard about the exchange. Based on responses from participants' ZIP code of residence, their county of residence was inferred and recoded into "Miami-Dade," "Broward," or "Other." For method by which participants found out about the exchange, participants were asked "Where did you hear about the IDEA Exchange?" and were presented the options of "Word of mouth,", "Online," "Fliers/newspaper," or "Referral from healthcare provider," from which they were allowed to make multiple selections.

For drug use behaviors, participants were asked at what age they first started using drugs, what drugs they injected 
in the past month, if they used prescription opioids prior to ever injecting drugs, how many times per day they injected drugs on average during the past month, and the location they most often injected during the past month. Injection drug use in the past month was assessed for the following substances: heroin, cocaine, speedballs (heroin and cocaine), methamphetamine, fentanyl/carfentanil, crack, painkillers/opioids, and any other drugs not listed. Additionally, participants were asked how often during the last month they used alcohol swabs or reused or shared needle/injection equipment when injecting. Responses for these questions utilized a 4-point Likert scale, with choices including "None of the time," "Some of the time," "Most of the time," or "All of the time." The response "None of the time" corresponded to participants' never practicing this behavior during the past month, "Some of the time" as less than $50 \%$ of the time when practicing this behavior, "Most of the time" as greater than $50 \%$ of the time when practicing this behavior, and "All of the time" as each time when practicing this behavior. Additionally, to assess overdose behavior, participants were asked if they had ever overdosed due to injection drug use. Those who had reported an overdose were asked the number of times they had overdosed, and an average number of times overdosed for these participants was calculated from this data.

For self-reported $\mathrm{HIV} / \mathrm{HCV}$ status, participants were asked for their prior $\mathrm{HIV} / \mathrm{HCV}$ status-negative, positive, or unknown. All participants were offered a fingerstick test for HIV using the OraQuick Advance ${ }^{\odot}$ Rapid HIV-1/2 Antibody Test and a fingerstick test for HCV using the OraQuick ${ }^{\ominus}$ HCV Rapid Antibody Test. Results were recorded as positive or negative. Those who identified as HIV-positive at baseline were asked if they were currently receiving HIV treatment.

For each question, participants were offered the option to refuse to answer, for which these responses were not included in the analysis.

\section{Statistical procedures}

Chi-square tests were used to evaluate the differences in sample distribution between the fixed site and mobile van unit. Fisher's exact test was used for variables containing responses with small sample sizes. Post hoc pairwise comparisons were performed for subgroup analyses using the Bonferroni correction $(p<0.005)$. Statistical significance was defined by $p$ values $<0.05$. Statistical analyses were performed using Stata ${ }^{\circ}$ v.12 (Stata Corp., College Station, TX).

\section{Results}

Seven hundred eighteen participants were enrolled during the study period, of which $591(82.3 \%)$ were enrolled at the fixed site and $127(17.7 \%)$ at the mobile van unit. Among all enrollees, $74.8 \%$ were male, $52.1 \%$ were
non-Hispanic White, $85.9 \%$ completed high school, 59.8\% were unemployed, $42.1 \%$ were homeless, $54.2 \%$ reported an annual household income of less than $\$ 15,000$, and the mean age was 38 years. Compared to participants enrolled at the fixed site, a greater percentage of PWID at the mobile van unit were female $(35.4 \%$ vs $22.8 \%, p=.002)$, non-Hispanic Black/African-American (18.1\% vs $4.9 \%, p<.001)$, currently homeless $(61.7 \%$ vs $38.7 \%, p<.001)$, and had been unemployed for greater than 1 year $(43.5 \%$ vs $31.5 \%, p=.031)$ (Table 1). Fifty-one percent of PWID enrolled at the mobile van unit reported an annual household income of less than $\$ 5000$, compared to $29.1 \%$ of PWID enrolled at the fixed site $(p<.001)$. Word of mouth was the most reported method of hearing about the exchange at both sites $(80.6 \%$ mobile van unit vs $67.4 \%$ fixed site). However, many more fixed site enrolled participants reported hearing about the exchange online ( $8.2 \%$ mobile van unit vs $26.9 \%$ fixed site, $p<.001$ ). Fewer mobile van unit enrolled participants were from Broward County (10.3\% mobile van unit vs $19.6 \%$ fixed site, $p=.031$ ). The two groups did not differ significantly by age, educational attainment, marital status, or sexual orientation.

With regards to injection drug use behavior, participants enrolled at the fixed site and mobile van unit differed significantly by their location of injection drug use, use of alcohol swabs when injecting drugs, reuse of needles and injection equipment, and use of prescription opioids prior to injection drug use. 54.3\% of PWID enrolled at the mobile van unit reported most often injecting drugs in a street, park, or parking lot vs $38.2 \%$ of PWID enrolled at the fixed site $(p<.001)$ (Table 2). In contrast, $51.9 \%$ of participants enrolled at the fixed site most often injected in a private home vs $33.7 \%$ of participants at the mobile van unit $(p$ $<.001$ ). Compared to enrollees at mobile site, enrollees at the fixed site reported a greater rate of using alcohol swabs $(29.6 \%$ vs $14.8 \%, p=.002)$ and reusing needles/injection equipment $(74.8 \%$ vs $63.6 \%, p=.003)$ at least "most of the time" when injecting drugs. $70.5 \%$ of PWID enrolled at the mobile van unit reported never using an alcohol swab prior to injecting compared to $44.0 \%$ of PWID at the fixed site $(p=.002)$. Additionally, $64.3 \%$ of participants enrolled at the fixed site reported using prescription opioids before ever initiating injection drug use, compared to $50.0 \%$ of mobile van unit participants $(p=.010)$. Heroin was the most common drug injected, reported by $82.4 \%$ of participants enrolled at the fixed site and $59.8 \%$ of participants at the mobile site. Participants enrolled at both sites did not differ significantly by age at first drug injection, types of drugs injected, or needle sharing behavior.

$52.4 \%$ of PWID enrolled at the mobile van unit self-reported a prior status of $\mathrm{HCV}$-positive compared to $41.0 \%$ of PWID enrolled at the fixed site $(p=.040)$ (Table 3). Participants at both sites did not differ significantly by HCV or HIV test result at enrollment, prior HIV status, or HIV treatment status. 
Table 1 Sociodemographic characteristics among participants at the Miami IDEA syringe exchange

\begin{tabular}{|c|c|c|c|c|}
\hline Characteristics & Sample total $n(\%)$ & Fixed site $n(\%)$ & Mobile van unit $n(\%)$ & $p$ value \\
\hline Total & $718(100.0)$ & $591(82.3)$ & $127(17.7)$ & \\
\hline \multicolumn{5}{|l|}{ Age } \\
\hline Mean \pm standard deviation & $38.44 \pm 11.04$ & $38.13 \pm 10.80$ & $39.92 \pm 12.06$ & 0.124 \\
\hline $18-24$ & $37(5.2)$ & $30(5.1)$ & $7(5.5)$ & \multirow[t]{6}{*}{0.611} \\
\hline $25-29$ & $132(18.5)$ & $111(18.9)$ & $21(16.5)$ & \\
\hline $30-39$ & $266(37.2)$ & $224(38.1)$ & $42(33.1)$ & \\
\hline $40-49$ & $162(22.7)$ & $131(22.3)$ & $31(24.4)$ & \\
\hline $50-59$ & $72(10.1)$ & $58(9.9)$ & $14(11.0)$ & \\
\hline$\geq 60$ & $46(6.4)$ & $34(5.8)$ & $12(9.4)$ & \\
\hline \multicolumn{5}{|l|}{ Gender } \\
\hline Male & $537(74.8)$ & $456(77.2)$ & $81(63.8)$ & \multirow[t]{2}{*}{0.002} \\
\hline Female & $180(25.2)$ & $135(22.8)$ & $45(35.4)$ & \\
\hline \multicolumn{5}{|l|}{ Race/ethnicity } \\
\hline Non-Hispanic White & $373(52.1)$ & $325(55.2)$ & $48(37.8)$ & \multirow[t]{4}{*}{$<0.001$} \\
\hline Non-Hispanic Black or African American & $52(7.3)$ & $29(4.9)$ & $23(18.1)$ & \\
\hline Hispanic, of any race & $261(3.6)$ & $214(36.3)$ & $47(37.0)$ & \\
\hline Other & $30(4.2)$ & $21(3.6)$ & $9(7.1)$ & \\
\hline \multicolumn{5}{|l|}{ Marital status } \\
\hline Single & $367(57.3)$ & $320(58.7)$ & $47(49.5)$ & \multirow[t]{4}{*}{0.050} \\
\hline Relationship & $143(22.3)$ & $119(21.8)$ & $24(25.2)$ & \\
\hline Married & $62(9.7)$ & $55(10.1)$ & $7(7.4)$ & \\
\hline Separated, divorced, or widowed & $68(10.6)$ & $51(9.4)$ & $17(17.9)$ & \\
\hline \multicolumn{5}{|l|}{ Sexual orientation } \\
\hline Heterosexual & $579(85.0)$ & $497(85.0)$ & $82(85.4)$ & \multirow[t]{3}{*}{0.575} \\
\hline Gay/lesbian & $57(8.4)$ & $51(8.7)$ & $6(6.3)$ & \\
\hline Bisexual & $45(6.6)$ & $37(6.3)$ & $8(8.3)$ & \\
\hline \multicolumn{5}{|l|}{ Educational attainment } \\
\hline Some high school or less & $93(14.1)$ & $78(13.7)$ & $15(16.5)$ & \multirow[t]{5}{*}{0.214} \\
\hline High school/GED & $231(35.1)$ & $192(33.8)$ & $39(42.9)$ & \\
\hline Some college/technical school & $178(27.0)$ & $160(28.2)$ & $18(19.8)$ & \\
\hline College graduate & $130(19.7)$ & $116(20.4)$ & $14(15.4)$ & \\
\hline Advanced degree & $27(4.1)$ & $22(3.9)$ & $5(5.5)$ & \\
\hline \multicolumn{5}{|l|}{ Employment status } \\
\hline Unemployed $>1$ year & $222(33.2)$ & $182(31.5)$ & $40(43.5)$ & \\
\hline Unemployed $<1$ year & $178(26.6)$ & $154(26.7)$ & $24(26.1)$ & \multirow[t]{3}{*}{0.031} \\
\hline Employed (salary, hourly, or self-employed) & $240(35.9)$ & $218(37.8)$ & $22(23.9)$ & \\
\hline Disability & $29(4.3)$ & $23(4.0)$ & $6(6.5)$ & \\
\hline \multicolumn{5}{|l|}{ Household income } \\
\hline$\$ 0-\$ 4999$ & $205(32.4)$ & $156(29.1)$ & $49(51.0)$ & \multirow[t]{6}{*}{0.001} \\
\hline$\$ 5000-\$ 14,999$ & $138(21.8)$ & $123(24.6)$ & 15 (15.6) & \\
\hline$\$ 15,000-\$ 29,999$ & $125(19.8)$ & $109(20.3)$ & $16(16.7)$ & \\
\hline$\$ 30,000-\$ 44,999$ & $75(11.9)$ & $70(13.1)$ & $5(5.2)$ & \\
\hline$\$ 45,000-\$ 74,999$ & $53(8.4)$ & $48(9.0)$ & $5(5.2)$ & \\
\hline$>\$ 75,000$ & $36(5.7)$ & $30(5.6)$ & $6(6.3)$ & \\
\hline
\end{tabular}


Table 1 Sociodemographic characteristics among participants at the Miami IDEA syringe exchange (Continued)

\begin{tabular}{|c|c|c|c|c|}
\hline Characteristics & Sample total $n(\%)$ & Fixed site $n(\%)$ & Mobile van unit $n(\%)$ & $p$ value \\
\hline \multicolumn{5}{|l|}{ Housing status } \\
\hline Currently homeless & $268(42.1)$ & $210(38.7)$ & $58(61.7)$ & \multirow[t]{2}{*}{$<0.001$} \\
\hline Not homeless & $368(57.9)$ & $332(61.3)$ & $36(38.3)$ & \\
\hline \multicolumn{5}{|l|}{ How heard about exchange ${ }^{1}$} \\
\hline Word of mouth & $433(69.5)$ & $354(67.4)$ & 79 (80.6) & \multirow[t]{4}{*}{$<0.001$} \\
\hline Online & $149(23.9)$ & $141(26.9)$ & $8(8.2)$ & \\
\hline Fliers/newspaper & $30(4.8)$ & $24(4.6)$ & $6(6.1)$ & \\
\hline Referral from healthcare provider & $11(17.7)$ & $6(1.1)$ & $5(5.1)$ & \\
\hline \multicolumn{5}{|l|}{ County of residence } \\
\hline Miami-Dade & $497(72.2)$ & $402(70.3)$ & $95(81.9)$ & \multirow[t]{3}{*}{0.031} \\
\hline Broward & $124(18.0)$ & $112(19.6)$ & $12(10.3)$ & \\
\hline Other & $67(9.7)$ & $58(10.1)$ & $9(7.8)$ & \\
\hline
\end{tabular}

${ }^{1}$ Totals may exceed $100 \%$ as participants were allowed to select multiple answers for this question

\section{Discussion}

The main findings of this study suggest that PWID enrolled at the fixed site and mobile van unit varied by sociodemographic and risk characteristics. The mobile van unit seemed to attract PWID from higher risk and harder to reach groups than the fixed site (i.e., more women, more African Americans, higher self-reported baseline HCV seropositivity, lower socioeconomic status, more homelessness, more public injection, less use of alcohol swabs) than the fixed site. There are several possible factors as to why the two modalities attract such varied clientele despite often being in close proximity. One is that the mobile van unit most frequently parks at locations more central to the center of the city's drug trade about 1 mile from the fixed site location, with the sites separated by the Interstate 95 freeway, a perceived or actual barrier to access. Another is that participants enrolled at the mobile van unit are actively recruited from the surrounding area via in-person engagement with street-level outreach and word-of-mouth to a greater extent than participants enrolled at the fixed site. This result is interesting considering that the mobile van unit enrolled most of its participants in the same neighborhood where the fixed site is located, suggesting that different modalities of syringe exchange programs attract PWID with differing characteristics. These results are consistent with Riley et al., (2000) which found that PWID characteristics varied when comparing a pharmacy-based syringe exchange site to a van site in Baltimore, Maryland [17].

These results provide an interesting insight and discussion into the present opioid crisis. Overtown, Miami, is predominantly an African-American neighborhood and has become a hotspot for the purchase of illicit drugs as well as drug overdoses as the opioid crisis has evolved. Interestingly, data collected from this study characterizes the exchange participants as largely white, with the fixed site attracting a larger proportion of white PWID. This is not reflective of the demographics of Overtown nor of PWID in Miami, according to census data and data from the Florida Department of Health, respectively [19, 20]. There has been evidence to suggest that the current opioid crisis, declared a public health emergency, has been notable due to the spread of heroin into predominantly white and middle-class neighborhoods as injection drug use was previously associated with marginalized urban minority populations [21, 22]. Additional data suggesting that fixed site PWID are from a higher socioeconomic status include the fact that nearly $20 \%$ of participants at the fixed site come from Broward County, and over one-quarter of PWID at the fixed site found out about the exchange online, evidence that participants at the fixed site may have greater access to transportation and the internet.

Additionally, a significantly greater proportion of PWID enrolled at the fixed site reported using prescription opioids prior to injection drug use. There is evidence to suggest that prior prescription opioid use may contribute to heroin dependence in a subset of PWID, contributing to the current opioid crisis [23, 24]. Our data suggests that the fixed site attracts a greater proportion of those making the progression from prescription opioid use to heroin. Notably, while a significantly greater proportion of PWID enrolled at the fixed site reported using an alcohol swab "most" or "all of the time" when injecting, they also reported a greater rate of reusing needles "all of the time" when injecting, compared to participants enrolled at the mobile van unit. The greater use of alcohol swabs among fixed-site enrolled PWID may reflect greater motivation for safe drug injection behaviors or greater availability to alcohol swabs. However, this safe injection practice does not seem to extend to reuse of needles or injection equipment and likely reflects the effects of drug paraphernalia laws and motivation for public disposal of syringes in 
Table 2 Drug use behaviors among participants at the Miami IDEA syringe exchange

\begin{tabular}{|c|c|c|c|c|}
\hline Characteristics & Sample total $n(\%)$ & Fixed site $n(\%)$ & Mobile van unit $n(\%)$ & $p$ value \\
\hline Total & $718(100.0)$ & $591(82.3)$ & $127(17.7)$ & \\
\hline \multicolumn{5}{|l|}{ Age at first drug injection } \\
\hline Mean \pm standard deviation & $24.65 \pm 8.80$ & $24.78 \pm 8.85$ & $23.70 \pm 8.44$ & 0.302 \\
\hline \multicolumn{5}{|l|}{ Drugs injected, past month ${ }^{1}$} \\
\hline Heroin & $563(78.4)$ & $487(82.4)$ & $76(59.8)$ & \multirow[t]{8}{*}{0.181} \\
\hline Cocaine & $187(26.0)$ & $153(25.9)$ & $34(26.8)$ & \\
\hline Speedball (heroin and cocaine) & $127(17.7)$ & $110(18.6)$ & $17(13.4)$ & \\
\hline Methamphetamine & $73(10.2)$ & $68(11.5)$ & $5(3.9)$ & \\
\hline Fentanyl/carfentanil & $71(9.9)$ & $60(10.2)$ & $11(8.7)$ & \\
\hline Crack & $59(8.2)$ & $47(8.0)$ & $12(9.4)$ & \\
\hline Prescription painkillers/opioids & $57(7.9)$ & $52(8.8)$ & $5(3.9)$ & \\
\hline Other & $24(3.3)$ & $19(3.2)$ & $5(3.9)$ & \\
\hline \multicolumn{5}{|c|}{ Prescription opioid use prior to injection drug use } \\
\hline Yes & $351(62.0)$ & $306(64.3)$ & $45(50.0)$ & 0.010 \\
\hline \multicolumn{5}{|c|}{ Location most often inject, past month } \\
\hline Private home & $303(49.2)$ & $272(51.9)$ & $31(33.7)$ & \multirow[t]{4}{*}{$<0.001$} \\
\hline Street, park, or parking lot & $250(40.6)$ & $200(38.2)$ & $50(54.3)$ & \\
\hline Public building/restroom & $48(7.8)$ & $43(8.2)$ & $5(5.4)$ & \\
\hline Other & $15(2.4)$ & $9(1.7)$ & $6(6.5)$ & \\
\hline \multicolumn{5}{|c|}{ Reuse needle/injection equipment when injecting, past month } \\
\hline None of the time & $48(7.7)$ & $36(6.8)$ & $12(13.6)$ & \multirow[t]{4}{*}{0.003} \\
\hline Some of the time & $118(19.0)$ & $98(18.4)$ & $20(22.7)$ & \\
\hline Most of the time & $135(21.8)$ & $109(20.5)$ & $26(29.5)$ & \\
\hline All of the time & $319(51.5)$ & $289(54.3)$ & $30(34.1)$ & \\
\hline \multicolumn{5}{|c|}{ Shared needle/injection equipment when injecting, past month } \\
\hline None of the time & $411(63.1)$ & $357(63.5)$ & $54(60.7)$ & \multirow[t]{4}{*}{0.608} \\
\hline Some of the time & $131(20.1)$ & $111(19.8)$ & $20(22.5)$ & \\
\hline Most of the time & $52(8.0)$ & $47(8.4)$ & $5(5.6)$ & \\
\hline All of the time & $57(8.8)$ & $47(8.4)$ & $10(11.2)$ & \\
\hline \multicolumn{5}{|c|}{ Used alcohol swab when injecting, past month } \\
\hline None of the time & $117(54.9)$ & $55(44.0)$ & $62(70.5)$ & \multirow[t]{4}{*}{0.002} \\
\hline Some of the time & $46(21.6)$ & $33(26.4)$ & $13(14.8)$ & \\
\hline Most of the time & $21(9.9)$ & $16(12.8)$ & $5(5.7)$ & \\
\hline All of the time & 29 (13.6) & $21(16.8)$ & $8(9.1)$ & \\
\hline
\end{tabular}

${ }^{1}$ Totals may exceed $100 \%$ as participants were allowed to select multiple answers for this question

Miami due to legal consequences of possession [25]. Overall, for participants enrolled at both sites, there was a high practice of risky injection behaviors, likely due to a preexisting lack of access to clean syringes and lack of harm reduction education prior to the opening of the IDEA Exchange. Such high-risk injection practices among PWID in Miami were shown to lead to significant healthcare expenditures due to bacterial complications of injection drug use prior to the exchange's opening [26].
Considering the present-day opioid crisis, communities may be looking to decrease their incidence of HIV by increasing access to sterile needles via SEPs. Considering the results of this study combined with the fact that PWID tend to be a hard-to-reach population, implementing mobile-based exchange along with fixed site exchange may increase the scope of an SEP. The current study does not have evidence to support one method over the other, however. Limitations to this study include the differing sample size between those enrolled at the fixed site and 
Table $3 \mathrm{HCV} / \mathrm{HIV}$ status among participants at the Miami IDEA syringe exchange

\begin{tabular}{|c|c|c|c|c|}
\hline Characteristics & Sample total n (\%) & Fixed site $n(\%)$ & Mobile van unit $n(\%)$ & $p$ value \\
\hline Total & $718(100.0)$ & $591(82.3)$ & $127(17.7)$ & \\
\hline \multicolumn{5}{|l|}{ Prior HCV status } \\
\hline Negative & $340(54.2)$ & $304(56.1)$ & $36(42.9)$ & \multirow[t]{3}{*}{0.040} \\
\hline Positive & $266(42.4)$ & $222(41.0)$ & $44(52.4)$ & \\
\hline Unknown & $21(3.3)$ & $16(3.0)$ & $5(5.9)$ & \\
\hline \multicolumn{5}{|l|}{ HCV test result } \\
\hline Positive & $69(28.5)$ & $59(27.6)$ & $10(35.7)$ & \multirow[t]{2}{*}{0.370} \\
\hline Negative & $173(71.5)$ & $155(72.4)$ & $18(64.3)$ & \\
\hline \multicolumn{5}{|l|}{ Prior HIV status } \\
\hline Negative & $584(88.1)$ & $516(88.7)$ & 68 (83.95) & \multirow[t]{3}{*}{0.412} \\
\hline Positive & $70(10.6)$ & $58(10.0)$ & $12(14.81)$ & \\
\hline Unknown & $9(1.4)$ & $8(1.4)$ & $1(1.23)$ & \\
\hline \multicolumn{5}{|l|}{ HIV test result } \\
\hline Positive & $2(0.6)$ & $2(0.70)$ & $0(0.0)$ & \multirow[t]{2}{*}{0.608} \\
\hline Negative & $344(99.4)$ & $304(99.4)$ & $40(100.0)$ & \\
\hline \multicolumn{5}{|c|}{ Currently in HIV treatment, if HIV positive } \\
\hline Yes & $48(82.8)$ & $39(83.0)$ & $9(81.8)$ & \multirow[t]{2}{*}{0.927} \\
\hline No & $10(17.2)$ & $8(17.0)$ & $2(18.2)$ & \\
\hline
\end{tabular}

mobile van unit as well as the fixed site data including enrollments from December 2016 while the mobile van unit data includes enrollments from its inception in April 2017. Additionally, the data is self-reported and is subject to social desirability bias, although IDEA Exchange staff are well-known and trusted by the PWID community in Miami so there should be a limited effect of this on our results.

This study provides significant conclusions as to the efficacy of mobile van units in targeting hard to reach populations in urban areas. Importantly, it provides further evidence on how best to reach those affected by the national opioid crisis, especially in states that have been late to adopt syringe exchange. Further studies will explore whether convenience or other factors such as transportation or stigma affect the sociodemographic makeup of the exchange participants. As the evidence regarding the efficacy of syringe exchange literature is scientific fact, and more states pass syringe exchange laws to combat this crisis, varied efforts to target PWID should be made. The present study suggests that multimodal delivery of syringe services to PWID may be vital to reducing the spread of HIV and other communicable diseases in light of our continuing opioid crisis.

\section{Acknowledgements}

We wish to thank the University of Miami for their support. We would also like to acknowledge the contributions of IDEA Exchange staff toward this project, specifically Carlos Padron, Emy Martinez, Phoebe Hughes, Jason Onugha, and Deandre Tate-Drummer.

\section{Funding}

This study was funded by the Sylvester Comprehensive Cancer Center at the University of Miami.
Availability of data and materials

The datasets analyzed during the current study are available from the corresponding author on request subject to approval.

\section{Authors' contributions}

The study was conceived by SI, AK, and HT. SI, AK, TB, DF, and HT all contributed to the writing of the manuscript. All authors have read and approved the final manuscript.

Ethics approval and consent to participate

The University of Miami Institutional Review Board determined that this study was not human subjects research.

Consent for publication

Not applicable.

\section{Competing interests}

The authors declare that they have no competing interests.

\section{Publisher's Note}

Springer Nature remains neutral with regard to jurisdictional claims in published maps and institutional affiliations.

\section{Author details}

${ }^{1}$ Department of Public Health Sciences, University of Miami Miller School of Medicine, Miami, FL, USA. ${ }^{2}$ Department of Anthropology, University of Miami College of Arts and Sciences, Coral Gables, FL, USA. ${ }^{3}$ Department of Medicine, Division of Infectious Diseases, University of Miami Miller School of Medicine, Miami, FL, USA.

Received: 9 October 2018 Accepted: 15 January 2019

Published online: 23 January 2019

\section{References}

1. Des Jarlais D, Friedman S. HIV epidemiology and interventions among injecting drug users. Int J STD AIDS. 1996; (Suppl 2):57-61.

2. Guydish J, Bucardo J, Clark G, Bernheim S. Evaluating needle exchange: a description of client characteristics, health status, program utilization, and 
HIV risk behavior. Subst Use Misuse. 1998;33:1 173-96. https://doi.org/10. 3109/10826089809062213.

3. US General Accounting Office (USGAO). Needle exchange programs: research suggests promise as an AIDS prevention strategy. Washington, DC: US Government Printing Office; 1993.

4. Watters JK, Estilo MJ, Clark GL, Lorvick J. Syringe and needle exchange as HIV/AIDS prevention for injection drug users. JAMA. 1994;271(2):115-20. https://doi.org/10.1001/jama.1994.03510260047027.

5. Vlahov D, Junge B. The role of needle exchange programs in HIV prevention. Public Health Rep. 1998;113(Suppl 1):75-80.

6. Lurie P, Drucker E. An opportunity lost: HIV infections associated with lack of a national needle-exchange programme in the USA. Lancet. 1997;349:604-8.

7. Witteveen E, Schippers G. Needle and syringe exchange programs in Amsterdam. Subst Use Misuse. 2006;41 (6-7):835-6. https//doi.org/10.1080/10826080600669553.

8. United States Department of Health and Human Services. Surgeon General's Review of Needle Exchange Science. http://www.csdp.org/ research/surgeongennex.pdf

9. Centers for Disease Control and Prevention. HIV Surveillance Report. vol. 26. https://www.cdc.gov/hiv/pdf/library/reports/surveillance/cdc-hivsurveillance-report-2014-vol-26.pdf. Published November. 2014;2015.

10. Florida Department of Health. HIV/AIDS services. HIV/AIDS. Annu Rep. 2014; http://www.floridahealth.gov/diseases-and-conditions/aids/surveillance/epiprofiles/2014/hivaids-annual-morbidity-2014.pdf.

11. Centers for Disease Control and Prevention. HIV Surveillance Report, 2015; vol. 27. https://www.cdc.gov/hiv/pdf/library/reports/surveillance/cdc-hivsurveillance-report-2015-vol-27.pdf. Published November 2016.

12. Centers for Disease Control and Prevention. HIV Surveillance Report, 2016 vol. 28. https://www.cdc.gov/hiv/pdf/library/reports/surveillance/cdc-hivsurveillance-report-2016-vol-28.pdf. Published November 2017.

13. Florida Department of Health in Miami-Dade County. HIV/AIDS Surveillance: HIV \& AIDS Cases Diagnosed from 2014 to 2016. http://miamidade. floridahealth.gov/programs-and-services/infectious-disease-services/hiv-aidsservices/_documents/Surveillance/Diag-AIDS-HIV-cases-2014-2016.pdf.

14. Tempalski B, Lieb S, Cleland CM, Cooper H, Brady JE. Friedman SR. HIV prevalence rates among injection drug users in 96 large US metropolitan areas, 1992-2002. J Urban Health. Jan 2009:86(1):132-54.

15. Florida Department of Health. HIV infection among those with an injection drug use-associated risk. Florida; 2014. http://www.floridahealth.gov/ diseases-and-conditions/aids/surveillance/_documents/hiv-aids-slide-sets/ 2014/idu-2014.pdf

16. Islam MM, Conigrave KM. Assessing the role of syringe dispensing machines and mobile van outlets in reaching hard-to-reach and high-risk groups of injecting drug users (IDUs): a review. Harm Reduct J. 2007;4:14. https://doi. org/10.1186/1477-7517-4-14.

17. Riley ED, Safaeian M, Strathdee SA, et al. Comparing new participants of a mobile versus a pharmacy-based needle exchange program. J Acquir Immune Defic Syndr. 2000;24:57-61.

18. Strike C, Miskovic M. Scoping out the literature on mobile needle and syringe programs - review of service delivery and client characteristics, operation, utilization, referrals, and impact. Harm Reduct J. 2018;15:6. https://doi.org/10.1186/s12954-018-0212-3.

19. Florida Department of Health. National HIV Behavioral Surveillance Among Injection Drug Users. http://www.floridahealth.gov/diseases-andconditions/ aids/prevention/_documents/behavioral-survellance/Florida-NHBS-IDU2Fact-Sheet.pdf.

20. Census 2010. City of Miami Planning \& Zoning. City of Miami. http://www. miamigov.com/planning/census2010.html.

21. Cicero TJ, Ellis MS, Surratt HL, Kurtz SP. The changing face of heroin use in the United States: a retrospective analysis of the past 50 years. JAMA Psychiatry. 2014;71:821-6.

22. Dasgupta N, Beletsky L, Ciccarone D. Opioid crisis: no easy fix to its social and economic determinants. Am J Public Health. 2018;108(2):182-6. https:// doi.org/10.2105/AJPH.2017.304187.

23. Compton WM, Jones CM, Baldwin GT. Relationship between nonmedical prescription-opioid use and heroin use. N Engl J Med 2016;374(2):154-163. https://doi.org/10.1056/NEJM ra1508490.

24. Kolodny A, Courtwright DT, Hwang CS, et al. The prescription opioid and heroin crisis: a public health approach to an epidemic of addiction. Ann Rev Public Health. 2015;36:559-74.

25. Tookes HE, Kral AH, Wenger LD, et al. A comparison of syringe disposal practices among injection drug users in a city with versus a city without needle and syringe programs. Drug Alcohol Depend. 2012;123(1-3):255-9. https://doi.org/10.1016/i.drugalcdep.2011.12.001

26. Tookes H, Diaz C, Li H, Khalid R, Doblecki-Lewis SA. Cost analysis of hospitalizations for infections related to injection drug use at a county safety-net hospital in Miami, Florida. PLOS ONE. 2015;10(6):e0129360. https://doi.org/10.1371/journal.pone.0129360. Paraskevis D, ed.

\section{Ready to submit your research? Choose BMC and benefit from:}

- fast, convenient online submission

- thorough peer review by experienced researchers in your field

- rapid publication on acceptance

- support for research data, including large and complex data types

- gold Open Access which fosters wider collaboration and increased citations

- maximum visibility for your research: over $100 \mathrm{M}$ website views per year

At $\mathrm{BMC}$, research is always in progress.

Learn more biomedcentral.com/submissions 